\title{
The Role of Economic Policy Uncertainties in Predicting Stock Returns and their Volatility for Hong Kong, Malaysia and South Korea*
}

\author{
Mehmet Balcilar $^{* *}$, Rangan Gupta ${ }^{* * *}$ Won Joong Kim ${ }^{* * *}$ and Clement Kyei ${ }^{* * * *}$
}

\section{Highlights}

- We analyze the predictability of stock return and its volatility of Hong Kong, Malaysia and South Korea

- We base on the measure of domestic and global economic policy uncertainties (EPU)

- Linear Granger causality tests fail to find evidence of predictability from EPU

- A nonparametric causality-in-quantiles test, however, finds strong evidence of causality

- Nonparametric test is found to be more robust relative to the standard linear causality test.

\begin{abstract}
This paper analyzes whether we can predict stock return and its volatility of Hong Kong, Malaysia and South Korea based on measures of domestic and global (China, the European Area, Japan, and the US) economic policy uncertainties (EPU). While, linear Granger causality tests fail to find evidence of predictability, barring the case of South Korean EPU predicting its own stock returns, when we use a nonparametric causality-in-quantiles test, strong evidence of causality is detected from the EPUs for stock return volatility of Malaysia, and both returns and volatility at certain parts of the conditional distributions for South Korea. There is no evidence of predictability from domestic and global EPUs for return and volatility of the Hong Kong stock market. Given the statistical evidence of nonlinearity in our data set, we consider the results from the nonparametric test as more robust relative to the standard linear causality test.
\end{abstract}

JEL Codes: C32; C53; E60; G12; G17

Keywords: Economic Policy Uncertainty; Stock Returns; Volatility; Linear Causality; Nonparametric Quantile Causality; Emerging Markets

\footnotetext{
${ }^{*}$ We would like to thank anonymous referees for many helpful comments. However, any remaining errors are solely ours.

** Department of Economics, Eastern Mediterranean University, Famagusta, via Mersin 10, Northern Cyprus, Turkey and Department of Economics, University of Pretoria, Pretoria, 0002, South Africa. Email: mehmet@mbalcilar.net.

${ }_{* * *}$ Department of Economics, University of Pretoria, Pretoria, 0002, South Africa. Email: rangan.gupta@up.ac.za.

**** Corresponding author. Department of Economics, Konkuk University, Seoul, Republic of Korea. Email: wikim72@,konkuk.ac.kr.

***** Department of Economics, University of Pretoria, Pretoria, 0002, South Africa. Email: kweku.shaker@gmail.com.
} 


\section{Introduction and Related Literature}

Stock return and its volatility (often dubbed a measure of uncertainty) are among the most important indicators for capital budgeting and portfolio management decisions, as they directly reflect companies' financial health and future prospects (Poon and Granger, 2003; Rapach and Zhou, 2013; Ben Nasr et al., 2016; Chiang and Chen, 2016; Jordan et al., 2016). Hence, predicting stock returns and volatility is of paramount importance to practitioners in finance. A variety of macroeconomic and financial variables has been used to predict stock returns (see Rapach and Zhou (2013) for a detailed literature review). In this regard, there is a very recent, but growing, related literature that has analyzed the role of uncertainty, either news-based or derived from structural models, in predicting stock return and its volatility. Volatility is not directly observable and, therefore, must be constructed from observable variables. While, there exists no clear-cut consensus in terms of which approach to use in constructing measures of uncertainty, the news-based measures of uncertainty, as developed by Baker et al., (2015) and Brogaard and Detzel (2015), seem to have gained tremendous popularity in various applications in macroeconomics and finance (see Redl, 2015, for a detailed review). This is most likely due to the fact that data (not only for the US, but also other European and emerging economies) based on this approach is easily and freely available for use, and does not require any complicated estimation of a model to generate it in the first place. To construct the index, Baker et al. (2015) and Brogaard and Detzel (2015) perform month-by-month searches of newspapers for terms related to economic and policy uncertainty.

In this regard, some mixed, primarily in-sample, international empirical evidence can be found in Antonakakis et al., (2013), Kang and Ratti (2013), Gupta et al., (2014), Bekiros, Gupta and Majumdar (2016), Brogaard and Detzel (2015), Chang et al., (2015), Chuliá et al., (2015), Jurado et al., (2015), Kang and Ratti (2015), Redl (2015), Bekiros, Gupta and Kyei (2016), Li et al., (2016), and Sum (2012c). All these above studies have related the own-country uncertainty with own-country stock returns. The few exceptions in this regard are: Sum (2012a), Mensi et al., (2014), Momim and Masih (2015), and Balcilar, Gupta and Kyei (2016),. While, Sum (2012a) relates US news-based economic policy uncertainty (EPU) with stock returns in the BRIC (Brazil, Russia, India and China) countries, Mensi et al., (2014) adds South Africa to the BRIC countries, while analyzing the impact of US EPU, besides other global shocks. Mensi et al., (2014), however, finds no evidence of the role of contemporaneous values of US EPU in explaining daily South African stock returns, based on a quantile regression framework. Momim and Masih (2015) fails to detect any long-run effect of EPU, they too, as in Sum (2012a), confirm 
short-run impact on the stock market of the BRICS. Balcilar, Gupta and Kyei (2016) uses a causality-in-quantiles approach to show that not only the EPU of South Africa, but also the EPUs of twenty other developed and emerging markets (Australia, Brazil, Canada, China, France, Germany, Hong Kong, India, Italy, Japan, Malaysia, Mexico, The Netherlands, South Korea, Spain, Sweden, Switzerland, UK and US), can predict South African stock returns over its entire conditional distribution, with the predictability being strongest around the median. ${ }^{1}$ In general, whether one uses domestic or foreign EPUs as predictors, the literature tends to suggest the need to use nonlinear models in predicting returns and volatility of stock markets, since the relationship of these variables with uncertainty cannot be captured appropriately with linear econometric models.

Against this backdrop, the objective of this paper is to use a recently proposed nonparametric causality-in-quantiles test by Balcilar et al., (2017) to analyze the role of EPU in predicting stock return and its volatility for the selected East Asian countries - namely, Hong Kong, Malaysia and South Korea- over the monthly period of 1997:01-2012:03. EPU data are available for five East Asian countries (China, Hong Kong, Japan, Malaysia and South Korea) and there were studies that analyzed the causal relationship between economic uncertainty and stock return in China and Japan (see, for example, Kang and Ratti (2015), Li et al. (2016), and Sum (2012b). We, therefore, focus on three East Asian countries: Hong Kong, Malaysia and South Korea. In this regard, we not only look at the respective domestic EPU of these countries, but also the role played by the EPU of China, the European Area, Japan, and the US. Note that, given a globalized financial system, it makes sense that we not only analyze the impact of the country-specific EPUs, but also the role of EPUs of the major economies in the world in predicting the stock return and its volatility of the selected East Asian countries that show high levels of financial openness. In other words, using our framework, we test: (a) whether EPU of country $i$, where $i=$ Hong Kong, Malaysia, and South Korea, affects returns and volatility of stock market of country $i$, and; (b) whether EPU of country $j$, where $j=$ China, the European Area, Japan, and the US, causes returns and volatility of country $i$. Since we standardize the domestic and foreign EPUs, we are also able to test whether global EPUs are more important than domestic EPU in predicting stock return and/or volatility of Hong Kong, Malaysia, and South Korea.

\footnotetext{
${ }^{1}$ Mensi et al., (2016), while analyzing the impact of country risk ratings on the stock returns of BRICS using dynamic panel threshold models, also failed to provide any significant evidence of the EPU of the US on stock returns of these countries. Interestingly, however, they did find a significant negative impact of the VIX (i.e., the volatility index of the S\&P500).
} 
This causality-in-quantiles test that we employ in this paper combines the frameworks of kth order nonparametric causality of Nishiyama et al., (2011) and nonparametric quantile causality of Jeong et al., (2012), and hence, can be considered to be a more general version of Nishiyama et al.'s (2011) test. As pointed out by Balcilar, Gupta, Sousa and Wohar (2017), the causality-inquantiles approach employed in our study has following novelties: Firstly, it is robust to misspecification errors as it detects the underlying dependence structure between the examined time series; this could prove to be particularly important, as it is well known (and as we also show below) that stock returns display nonlinear dynamics. Secondly, via this methodology, we test for causality that may exist in the tails of the joint distribution of the variables, thus not only for causality-in-mean (1st moment). Finally, we are also able to investigate causality-in-variance thereby volatility spillovers, as some times when causality in the conditional mean may not exist, yet higher order interdependencies may emerge as frequently observed for financial time series data. To the best of our knowledge, this is the first paper to employ a nonparametric causality-inquantile approach to study the predictability of both stock returns and its volatility simultaneously based on domestic and global EPUs for Hong Kong, Malaysia and South Korea. Earlier studies involving predictability of stock returns and volatility for these three economies have either used univariate models or multivariate models comprising of macroeconomic, financial and international variables as predictors. In this regard, see for example the following recent studies, and the references cited therein: Jarrett (2008), Poon and Tong (2010), Jais et al., (2012), Tarazi and Gallato (2012), Tsai (2012), Zakaria and Shamsuddin (2012), Choi et al., (2013), Gebka and Wohar (2013), and Han et al. (2015). Specifically, Jarrett (2008) analyzed the effects of daily dummies, trade volumes and trade values on stock returns for Hong Kong and Japan stock markets. Poon and Tong (2010) estimated the effects of output growth, inflation and interest rate on stock return and volatility for Malaysia, India, Korea and the Philippines. Jais et al. (2012) analyzed whether accounting information, such as price-earnings ratio, return of equity, debt to equity, earning growth and price to net tangible asset, can predict stock returns for Malaysia. Tarazi and Gallato (2012) investigated whether financial ratios, such as price to earnings, book-to-market ratios and return on asset, together with exchange rate and interest rate, can predict stock market returns for Thailand and Malaysia. Tsai (2012) investigate the relationship between exchange rate and stock price index for six Asian countries (Singapore, Thailand, Malaysia, the Philippines, South Korea and Taiwan). Zakaria and Shamsuddin (2012) analyzed the relationship between stock market returns volatility and five macroeconomic volatilities of GDP, inflation, exchange rate, interest rates and money supply for Malaysia. Choi et al. (2013) investigated the domestic and cross-country relationship between stock returns and trading 
volumes for Korea, Japan, China and Hong Kong. Gebka and Wohar (2013) also analyzed the relationship between trading volume and stock returns for Pacific Basin countries. Han et al. (2015) analyzed whether macro-finance variables, such as USD/KRW exchange returns, interest rates, credit spreads, term spreads, KOSPI 200 index, S\&P 500, US VIX index), can predict Korea's implied volatility (VKOSPI) which is derived from KOSPI 200 options.

But none of these studies have looked at the impact of measures of uncertainty on these stock markets, which as we discuss below are shown to affect domestic business cycles and also global investment flows. In addition, whether univariate or multivariate methods that were applied in the above-mentioned studies dealing with Hong Kong, Malaysia and South Korea, these approaches were conditional-mean based methods. While conditional mean-based methods are of importance, but they fail to capture the phases of the stock markets, and hence cannot provide a time-varying nature of the analysis. Our quantiles-based approach is able to model bear, normal and bull regimes for stock returns, and low, normal and high volatilities, i.e., risks through the lower quantile, median and upper quantile. Hence, our approach is clearly more informative, and is more appropriate than conditional-mean based analysis with stock markets having heavy tails, which conditional mean-based models cannot capture and hence, can provide an incomplete picture of predictability analysis.

A relevant question, to ask at this stage is: What is the theoretical background that causes one to believe that EPU (both domestic and global) can predict stock returns? Asset returns are functions of the state variables of the real economy, and the real economy itself displays significant fluctuations. Besides standard theoretical justifications of such fluctuations based on productivity and/or policy shocks, a recent strand of literature relates the impact of various forms of policy-generated uncertainty, to movements in macroeconomic variables (Bloom, 2009; Aastviet et al., 2014; Colombo, 2013; Jones and Olson, 2013, Mumtaz and Zanetti, 2013; Karnizova and Li, 2014; Alessandri and Mumtaz, 2014; Mumtaz and Surico, 2013; Balcilar et al., 2014, 2015; Carriero et al., 2015; Mumtaz and Theodoridis, 2014, 2015; Jurado et al., 2015; Redl, 2015; Rossi and Sekhposyan, 2015), which in turn, is expected to affect stock returns. While this explanation relates to the role a country's own EPU can play in affecting its stock returns, we also need to understand why EPU of another country or region might predict stock returns of Hong Kong, Malaysia and South Korea. A possible answer to this question emanates from the following lines of thinking: These three countries are subjected to global investment flows, hence, as changes in the EPU of a specific foreign country or region affects that economy's domestic and global investment potential, it is likely to feed into growth process and stock markets of Hong Kong, Malaysia and South Korea (Balcilar, Gupta and Kyei, 2015). Moreover, 
international investors are interested in these emerging stock markets for risk diversification opportunities, which in turn, provide a direct channel through which a change in the EPU of a foreign nation or region, can affect stock returns of Hong Kong, Malaysia and South Korea (Balcilar, Gupta and Kyei, 2015). In other words, foreign EPUs are expected to affect the stock returns of these three economies, given the increased economic integration of the world economy in general, and the financial markets in particular. The remainder of the paper is organized as follows: Section 2 presents the methodology, while Section 3 discusses the data and the results. Finally, Section 4 concludes.

\section{Methodology}

We present here a novel methodology, as proposed by Balcilar et al., (2017), for the detection on nonlinear causality via a hybrid approach based on the frameworks of Nishiyama et al. (2011) and Jeong et al. (2012). We denote stock returns of Hong Kong, Malaysia, or South Korea as $\left(y_{t}\right)$ and own-country EPU (of Hong Kong, Malaysia, or South Korea) or foreign- EPU (China, Euro area, Japan and US) as $\left(\chi_{t}\right.$. Following Jeong et al. (2012), the quantile-based causality is defined as follows: ${ }^{2}$

$x_{t}$ does not cause $y_{t}$ in the $\theta$-quantile with respect to the lag-vector of $\left\{y_{t-1}, \ldots, y_{t-p}, x_{t-1}, \ldots, x_{t-p}\right\}$ if

$$
Q_{\theta}\left\{y_{t} \mid y_{t-1}, \ldots, y_{t-p}, x_{t-1}, \ldots, x_{t-p}\right\}=Q_{\theta}\left\{y_{t} \mid y_{t-1}, \ldots, y_{t-p}\right\}
$$

$x_{t}$ is a prima facie cause of $y_{t}$ in the $\theta^{\text {th }}$ quantile with respect to $\left\{y_{t-1}, \ldots, y_{t-p}, x_{t-1}, \ldots, x_{t-p}\right\}$ if

$$
Q_{\theta}\left\{y_{t} \mid y_{t-1}, \ldots, y_{t-p}, x_{t-1}, \ldots, x_{t-p}\right\} \neq Q_{\theta}\left\{y_{t} \mid y_{t-1}, \ldots, y_{t-p}\right\}
$$

where $Q_{\theta}\left\{y_{t} \mid \cdot\right\}$ is the $\theta$ th quantile of $y_{t}$ depending on $t$ and $0<\theta<1$.

Let $Y_{t-1} \equiv\left(y_{t-1}, \ldots, y_{t-p}\right), X_{t-1} \equiv\left(x_{t-1}, \ldots, x_{t-p}\right), Z_{t}=\left(X_{t}, Y_{t}\right), F_{y_{t} \mid Z_{t-1}}\left(y_{t}, Z_{t-1}\right)$ and $F_{y_{t} \mid Y_{t-1}}\left(y_{t}, Y_{t-1}\right)$ denote the conditional distribution functions of $y_{t}$ given $Z_{t-1}$ and $Y_{t-1}$ respectively. The conditional distribution $F_{y_{t} \mid Z_{t-1}}\left(y_{t}, Z_{t-1}\right)$ is assumed to be absolutely continuous in $y_{t}$ for almost all $Z_{t-1}$. If we denote $Q_{\theta}\left(Z_{t-1}\right) \equiv Q_{\theta}\left(y_{t} \mid Z_{t-1}\right)$ and $Q_{\theta}\left(Y_{t-1}\right) \equiv Q_{\theta}\left(y_{t} \mid Y_{t-1}\right)$, we have

\footnotetext{
${ }^{2}$ The exposition in this section closely follows Nishiyama et al. (2011) and Jeong et al. (2012).
} 
$F_{y_{t} \mid Z_{t-1}}\left\{Q_{\theta}\left(Z_{t-1}\right) \mid Z_{t-1}\right\}=\theta$ with probability one. Consequently, the hypotheses to be tested based on definitions (1) and (2) are:

$$
\begin{aligned}
& H_{0}=P\left\{F_{y_{t} \mid Z_{t-1}}\left\{Q_{\theta}\left(Y_{t-1}\right) \mid Z_{t-1}\right\}=\theta\right\}=1 \\
& H_{1}=P\left\{F_{y_{t} \mid Z_{t-1}}\left\{Q_{\theta}\left(Y_{t-1}\right) \mid Z_{t-1}\right\}=\theta\right\}<1
\end{aligned}
$$

Jeong et al. (2012) employs the distance measure $J=\left\{\varepsilon_{t} E\left(\varepsilon_{t} \mid Z_{t-1}\right) f_{Z}\left(Z_{t-1}\right)\right\}$ where $\varepsilon_{t}$ is the regression error term and $f_{Z}\left(Z_{t-1}\right)$ is the marginal density function of $Z_{t-1}$. The regression error $\varepsilon_{t}$ emerges based on the null in (3), which can only be true if and only if $E\left[\mathbf{1}\left\{y_{t} \leq Q_{\theta}\left(Y_{t-1}\right) \mid Z_{t-1}\right\}\right]=\theta$ or equivalently $\mathbf{1}\left\{y_{t} \leq Q_{\theta}\left(Y_{t-1}\right)\right\}=\theta+\varepsilon_{t}$, where $\mathbf{1}\{\cdot\}$ is an indicator function. Jeong et al. (2012) specify the distance function as follows:

$$
J=E\left[\left\{F_{y_{t} \mid Z_{t-1}}\left\{Q_{\theta}\left(Y_{t-1}\right) \mid Z_{t-1}\right\}-\theta\right\}^{2} f_{Z}\left(Z_{t-1}\right)\right]
$$

In Eq. (5), it is important to note that $J \geq 0$ i.e., the equality holds if and only if $H_{0}$ in (3) is true, while $J>0$ holds under the alternative $H_{1}$ in Eq. (4). Jeong et al. (2012) show that the feasible kernel-based test statistic for $J$ has the following form:

$$
\hat{J}_{T}=\frac{1}{T(T-1) h^{2 p}} \sum_{t=p+1}^{T} \sum_{s=p+1, s \neq t}^{T} K\left(\frac{Z_{t-1}-Z_{s-1}}{h}\right) \hat{\varepsilon}_{t} \hat{\varepsilon}_{s}
$$

where $K(\cdot)$ is the kernel function with bandwidth $h, T$ is the sample size, $p$ is the lag-order, and $\hat{\varepsilon}_{t}$ is the estimate of the unknown regression error, which is estimated as follows:

$$
\hat{\varepsilon}_{t}=1\left\{y_{t} \leq Q_{\theta}\left(Y_{t-1}\right)-\theta\right\}
$$

$\hat{Q}_{\theta}\left(Y_{t-1}\right)$ is an estimate of the $\theta$ th conditional quantile of $y_{t}$ given $Y_{t-1}$. Below, we estimate $\hat{Q}_{\theta}\left(Y_{t-1}\right)$ using the nonparametric kernel method as:

$$
\hat{Q}_{\theta}\left(Y_{t-1}\right)=\hat{F}_{y_{t} \mid Y_{t-1}}^{-1}\left(\theta \mid Y_{t-1}\right)
$$

where $\hat{F}_{y_{t} \mid Y_{t-1}}\left(y_{t} \mid Y_{t-1}\right)$ is the Nadarya-Watson kernel estimator given by: 


$$
\hat{F}_{y_{t} \mid Y_{t-1}}\left(y_{t} \mid Y_{t-1}\right)=\frac{\sum_{s=p+1, s \neq t}^{T} L\left(\left(Y_{t-1}-Y_{s-1}\right) / h\right) 1\left(y_{s} \leq y_{t}\right)}{\sum_{s=p+1, s \neq t}^{T} L\left(\left(Y_{t-1}-Y_{s-1}\right) / h\right)}
$$

with $L(\cdot)$ denoting the kernel function and $h$ the bandwidth.

In an extension of the Jeong et al. (2012) framework, we develop a test for the 2nd moment. In particular, we want to test the volatility causality between either own- or foreigncountry EPU and stock returns. Causality in the $k^{\text {th }}$ moment generally implies causality in the $m$ th moment for $k<m$. Firstly, we employ the nonparametric Granger quantile causality approach by Nishiyama et al. (2011). For a $\left(y_{t}\right)$ process they assume that:

$$
y_{t}=g\left(Y_{t-1}\right)+\sigma\left(X_{t-1}\right) \varepsilon_{t}
$$

where $\varepsilon_{t}$ is a white noise process; and $g(\cdot)$ and $\sigma(\cdot)$ are unknown functions that satisfy certain conditions for stationarity. However, this specification does not allow for Granger-type causality testing from $x_{t}$ to $y_{t}$, but could possibly detect the "predictive power" from $x_{t}$ to $y_{t}^{2}$ when $\sigma(\cdot)$ is a general nonlinear function. Hence, the Granger causality-in-variance definition does not require an explicit specification of squares for $X_{t-1}$. We re-formulate Eq. (10) into a null and alternative hypothesis for causality in variance as follows:

$$
\begin{aligned}
& H_{0}=P\left\{F_{y_{t}^{2} \mid Z_{t-1}}\left\{Q_{\theta}\left(Y_{t-1}\right) \mid Z_{t-1}\right\}=\theta\right\}=1 \\
& H_{1}=P\left\{F_{y_{t}^{2} \mid Z_{t-1}}\left\{Q_{\theta}\left(Y_{t-1}\right) \mid Z_{t-1}\right\}=\theta\right\}<1
\end{aligned}
$$

To obtain a feasible test statistic for testing the null in Eq. (10), we replace $y_{t}$ in Eq. (6) - (9) with $y_{t}^{2}$. Incorporating the Jeong et al. (2012) approach we overcome the problem that causality in the conditional 1st moment (mean) imply causality in the 2nd moment (variance). In order to overcome this problem, we specify the causality in higher order moments using the following model:

$$
y_{t}=g\left(X_{t-1}, Y_{t-1}\right)+\varepsilon_{t}
$$

Thus, higher order quantile causality can be specified as: 


$$
\begin{gathered}
H_{0}=P\left\{F_{y_{t}^{k} \mid Z_{t-1}}\left\{Q_{\theta}\left(Y_{t-1}\right) \mid Z_{t-1}\right\}=\theta\right\}=1 \quad \text { for } k=1,2, \ldots, K \\
H_{1}=P\left\{F_{y_{t}^{k} \mid Z_{t-1}}\left\{Q_{\theta}\left(Y_{t-1}\right) \mid Z_{t-1}\right\}=\theta\right\}<1 \quad \text { for } k=1,2, \ldots, K
\end{gathered}
$$

Integrating the entire framework, we define that $x_{t}$ Granger causes $y_{t}$ in quantile $\theta$ up to $K^{\text {th }}$ moment utilizing Eq. (11) to construct the test statistic of Eq. (6) for each $k$. However, it can be shown that it is not easy to combine the different statistics for each $k=1,2, \ldots, K$ into one statistic for the joint null in Eq. (14) because the statistics are mutually correlated (Nishiyama et al., 2011). To efficiently address this issue, we include a sequential-testing method as described Nishiyama et al. (2011) with some modifications. Firstly, we test for the nonparametric Granger causality in the 1 st moment $(k=1)$. Rejecting the null of non-causality means that we can stop and interpret this result as a strong indication of possible Granger quantile causality-in-variance. Nevertheless, failure to reject the null for $k=1$, does not automatically leads to no-causality in the 2 nd moment, thus we can still construct the tests for $k=2$. Finally, we can test the existence of causality-in-variance, or the causality-in-mean and variance successively.

Intuitively speaking, our approach thus allows us to test for the ability of domestic or global EPUs $\left(x_{t}\right)$ in predicting movements of the stock returns $\left(y_{t}\right)$ and volatility $\left(y_{t}^{2}\right)$ of Hong Kong, Malaysia and South Korea over the entire conditional distribution of returns and volatility, i.e., by looking at various quantiles $(\theta)$ of their respective distributions. In the process, we are able to go beyond standard conditional mean-based Granger causality test and study the various phases of the equity markets (i.e., quantiles of conditional distributions) of these countries while analyzing the impact of EPUs. In addition, with our approach being a nonparametric one, we are able to control for any misspecification in the linear model due to nonlinearity and structural breaks.

The empirical implementation of causality testing via quantiles entails specifying three important choices: the bandwidth $h$, the lag order $p$, and the kernel type for $K(\cdot)$ and $L(\cdot)$ in Eq. (6) and (9) respectively. In our study, the lag order of 1 is determined using the Schwarz Information Criterion (SIC) under a bivariate VAR comprising of stock returns and either ownor foreign-country EPU. The choice of this lag-length is also in line with predictive regression framework in the stock returns predictability literature discussed in the introduction. The bandwidth value is selected using the least squares cross-validation method. Lastly, for $K(\cdot)$ and $L(\cdot)$ we employ Gaussian-type kernels. 


\section{Data and Empirical Results}

Our analysis is based on monthly stock prices of Hong Kong, Malaysia and South Korea, and the respective EPU of these countries, as well as the EPU of China, the European area, Japan and the US. The data on stock index for these three countries are obtained from the International Financial Statistics database of the International Monetary Fund. Since stock prices were non-stationary, based on standard unit root tests as reported in Table A1 in the Appendix of the paper, we work with stock returns, which are in turn, obtained as the first-differences of the natural logarithmic values of the stock indexes expressed in percentages. ${ }^{3}$ The data on EPU for all the countries, barring the European Area, is derived from Brogaard and Detzel (2015). ${ }^{4}$ The authors construct the EPU indexes based on data from an internet search and count of articles that use key words associated with economic policy uncertainty in these countries. The source for their data is the Access World News database. The data for the EPU of the European Area comes from Baker et al., (2015), available for download at: http://www.policyuncertainty.com/europe monthly.html. The European Area index is based on newspaper articles that contained the terms: uncertain or uncertainty, economic or economy, and one or more policy-relevant terms for France, Germany, Italy, Spain, the Netherlands and the UK. To construct this index, Baker et al., (2015) draws information on policy uncertainty from the following country-specific newspapers: Le Monde and Le Figaro for France, Handelsblatt and Frankfurter Allgemeine Zeitung for Germany, Corriere Della Sera and La Repubblica for Italy, El Mundo and El Pais for Spain, Algemeen Dagblad, NRC Handelsblad, De Telegraaf, Trouw, and De Volkskrant for the Netherlands, and The Times of London and Financial Times for the United Kingdom. Note that, the primary source for Baker et al., (2015) is also the Access World News database as in Brogaard and Detzel (2015), hence there is likely to be no inconsistency across these two studies, with the approach being also similar in terms of quantifying newspaper articles dealing with economic uncertainty related to policy-making. Given that Brogaard and Detzel (2015) did not create an index for the aggregate Euro area, we had to rely on Baker et al., (2015).

The data, starts from 1997:01 and stretches till 2012:03 (i.e., 183 observations), with the start and end data being purely driven by data availability of these two variables. We work with natural

\footnotetext{
${ }^{3}$ Note that the ADF test shows that the stock price of Hong Kong and South Kore are trend stationary. However, when we look at more powerful unit root tests, like the Phillips-Perron, DF-GLS and Ng-Perron tests, we see that stock prices for these two countries are indeed non-stationary.

${ }^{4}$ We thank Jonathan Brogaard for providing us with the EPU data. Note that, though Brogaard and Detzel (2015) created the EPU for 21 countries in an earlier version of the paper, they only concentrated on the US stock market in the published version.
} 
logarithmic levels of the EPU indexes, which, in turn are found to be stationary, based on standard unit root tests, as can be seen from Table A1 in the Appendix of the paper. Hence, the basic condition of stationarity of the variables required for our causality-in-quantiles approach holds with stock returns and the various EPU indexes. The data has been plotted in Figure A1 of the Appendix of the paper. In addition, since we want to compare the strengths of the various EPUs in affecting stock return and volatility of Hong Kong, Malaysia and South Korea, we standardize the natural logarithmic values of the EPU by dividing with their respective standard deviations.

Table 1 provides the summary statistics of the stock returns of Malaysia, Hong Kong and South Korea, their respective EPUs and the same for the global economies. South Korea has the highest mean for the stock returns, while Malaysia has the lowest mean returns, and in terms of riskiness, South Korea has the highest volatility, while, Hong Kong has the lowest value in this regard. The distribution of the stock returns is found to be negatively skewed, and possess excess kurtosis, yielding significant Jarque-Bera statistics for all the three countries; whereby the null of normality is overwhelmingly rejected at 1 percent level of significance for Hong Kong and Malaysia, and at 5 percent level of significance for South Korea. This, in turn, is indicative of a heavy left-tail for the stock returns in these three countries, and provides an initial motivation to look at the effect of the EPUs over the entire conditional distribution of stock returns, rather than just in the conditional-mean. The European Area EPU has both highest mean and volatility, while Japan has the lowest mean EPU, and the US EPU has the lowest volatility. Interestingly, barring the European Area EPU, all EPUs are normally distributed.

Table 1. Summary Statistics

\begin{tabular}{|c|c|c|c|c|c|c|c|c|c|c|}
\hline Statistic & $\begin{array}{c}\text { Stock } \\
\text { returns } \\
\text { Malaysia }\end{array}$ & $\begin{array}{c}\text { Stock } \\
\text { returns } \\
\text { Hong } \\
\text { Kong }\end{array}$ & $\begin{array}{c}\text { Stock } \\
\text { returns } \\
\text { South } \\
\text { Korea }\end{array}$ & $\begin{array}{c}\text { EPU } \\
\text { Malaysia }\end{array}$ & $\begin{array}{l}\text { EPU } \\
\text { Hong } \\
\text { Kong }\end{array}$ & $\begin{array}{l}\text { EPU } \\
\text { South } \\
\text { Korea }\end{array}$ & $\begin{array}{c}\text { EPU } \\
\text { European } \\
\text { Area }\end{array}$ & $\begin{array}{l}\text { EPU } \\
\text { China }\end{array}$ & $\begin{array}{l}\text { EPU } \\
\text { Japan }\end{array}$ & $\begin{array}{l}\text { EPU } \\
\text { United } \\
\text { States }\end{array}$ \\
\hline Mean & 0.139 & 0.254 & 0.587 & 2.951 & 3.326 & 2.639 & 4.718 & 2.970 & 2.867 & 2.875 \\
\hline Median & 0.874 & 0.861 & 1.685 & 2.972 & 3.322 & 2.623 & 4.637 & 2.949 & 2.858 & 2.866 \\
\hline Maximum & 29.442 & 18.615 & 20.712 & 4.136 & 3.792 & 3.321 & 5.807 & 3.435 & 3.385 & 3.241 \\
\hline Minimum & -28.463 & -26.06 & -23.582 & 2.005 & 2.806 & 1.94 & 3.9 & 2.477 & 2.209 & 2.634 \\
\hline Std. Dev. & 7.505 & 6.726 & 7.649 & 0.366 & 0.192 & 0.249 & 0.412 & 0.163 & 0.186 & 0.114 \\
\hline Skewness & -0.042 & -0.42 & -0.313 & 0.156 & -0.048 & 0.049 & 0.468 & 0.084 & -0.017 & 0.285 \\
\hline Kurtosis & 6.236 & 4.339 & 3.665 & 3.094 & 2.699 & 3.127 & 2.523 & 2.992 & 3.464 & 2.778 \\
\hline Jarque-Bera & 79.917 & 19.057 & 6.361 & 0.806 & 0.76 & 0.197 & 8.427 & 0.215 & 1.652 & 2.85 \\
\hline Probability & 0.000 & 0.000 & 0.042 & 0.668 & 0.684 & 0.906 & 0.015 & 0.898 & 0.438 & 0.241 \\
\hline Observations & 183 & 183 & 183 & 183 & 183 & 183 & 183 & 183 & 183 & 183 \\
\hline
\end{tabular}

Note: Std. Dev.: Standard Deviation. 
Though our objective is to analyze the causality-in-quantiles running from EPU to the stock return and its volatility, for the sake of completeness and comparability, we also conducted the standard linear Granger causality test based on a bivariate $\operatorname{VAR}(1)$ model comprising of returns and domestic or global EPUs in turn. The results have been reported in Table 2. As can be seen, barring the cases of the South Korean stock returns being predicted by its own EPU, there is no evidence of predictability originating from the EPUs for stock returns in the other cases at the conventional 5 percent level of significance. If the cut-off limit is weakened to 10 percent, we observe that the US EPU causes the stock returns of Malaysia. Overall, the evidence is weak, if not non-existent, in terms of the ability of domestic and global EPU to predict stock returns in the three economies under consideration.

Table 2. Linear Granger Causality Test

\begin{tabular}{lcc}
\hline Null hypothesis: & $F$-statistic & $p$-value \\
\hline Hong Kong stock returns not caused by: & & \\
\hline EPU China & 0.9790 & 0.3238 \\
\hline EPU European Area & 0.2211 & 0.6388 \\
\hline EPU Japan & 0.1857 & 0.6671 \\
\hline EPU Hong Kong & 0.1381 & 0.7106 \\
\hline EPU US & 0.3389 & 0.5612 \\
\hline Malaysian stock returns not caused by: & & \\
\hline EPU China & 0.0175 & 0.8950 \\
\hline EPU European Area & 0.6348 & 0.4267 \\
\hline EPU Japan & 1.5043 & 0.2216 \\
\hline EPU Malaysia & 0.0259 & 0.8725 \\
\hline EPU US & 2.8861 & 0.0911 \\
\hline South Korean stock returns not caused by: & & \\
\hline EPU China & 0.9700 & 0.3260 \\
\hline EPU European Area & 1.7332 & 0.1897 \\
\hline EPU Japan & 0.4781 & 0.4902 \\
\hline EPU South Korea & $3.9382 * *$ & 0.0487 \\
\hline EPU US & 0.5463 & 0.4608 \\
\hline
\end{tabular}

Note: In all cases, dependent variable are the stock returns of individual countries and the independent variable is the EPUs; ${ }^{* *}$ denotes rejection of the null hypothesis at $5 \%$ level of significance.

Next, to motivate the use of the nonparametric quantile-in-causality approach, we statistically investigate the possibility of nonlinearity in the relationship between the stock returns and the EPUs. To this end, we apply the Brock et al., (1996, BDS) test on the residuals of an AR(1) model for stock returns, and the stock returns equation in the VAR(1) model involving the various EPUs by turn. The BDS test, reported in Table 3, overwhelming rejects the null of serial dependence at various dimensions, at the highest levels of significance, for all cases considered. 
These results provide strong evidence of nonlinearity in the stock returns of these three countries, and in its relationship with its own EPU, and the EPUs of China, the European Area, Japan and the US. This means that, the results based on the linear Granger causality test, cannot be deemed robust and reliable.

Table 3. BDS Test of Nonlinearity

\begin{tabular}{|c|c|c|c|c|c|}
\hline & \multicolumn{5}{|c|}{ Dimension } \\
\hline & 2 & 3 & 4 & 5 & 6 \\
\hline $\begin{array}{c}\text { AR(1): Hong } \\
\text { Kong }\end{array}$ & $3.4915^{* * *}$ & $3.8405^{* * *}$ & $4.3527^{* * *}$ & $5.2434^{* * *}$ & $5.9671^{* * *}$ \\
\hline VAR(1): China & $3.5538^{* * *}$ & $4.0627^{* * *}$ & $4.6398^{* * *}$ & $5.5408^{* * *}$ & $6.2548^{* * *}$ \\
\hline $\begin{array}{c}\text { VAR(1): } \\
\text { European Area }\end{array}$ & $3.3303^{* * *}$ & $3.6918^{* * *}$ & $4.1925^{* * *}$ & $5.0217^{* * *}$ & $5.6609^{* * *}$ \\
\hline $\begin{array}{l}\text { VAR(1): Hong } \\
\text { Kong }\end{array}$ & $3.5008^{* * *}$ & $3.9947^{* * *}$ & $4.5142^{* * *}$ & $5.4332^{* * *}$ & $6.1950^{* * *}$ \\
\hline VAR(1): Japan & $3.3257^{* * *}$ & $3.8286^{* * *}$ & $4.3499^{* * *}$ & $5.2383^{* * *}$ & $5.9210^{* * *}$ \\
\hline VAR(1): US & $3.5675^{* * *}$ & $3.8644^{* * *}$ & $4.3637^{* * *}$ & $5.1564^{* * *}$ & $5.7424^{* * *}$ \\
\hline AR(1): Malaysia & $4.4673^{* * *}$ & $6.1097^{* * *}$ & $7.2457^{* * *}$ & $8.0024^{* * *}$ & $8.8772^{* * *}$ \\
\hline VAR(1): China & $4.4994^{* * *}$ & $6.1491^{* * *}$ & $7.2978^{* * *}$ & $8.0756^{* * *}$ & $8.9614^{* * *}$ \\
\hline $\begin{array}{c}\text { VAR(1): } \\
\text { European Area }\end{array}$ & $4.2031^{* * *}$ & $6.0075^{* * *}$ & $7.1467^{* * *}$ & $7.8891^{* * *}$ & $8.6907^{* * *}$ \\
\hline VAR(1): Japan & $4.1388^{* * *}$ & $6.0301^{* * *}$ & $7.3084^{* * *}$ & $8.0909^{* * *}$ & $8.9493^{* * *}$ \\
\hline VAR(1): Malaysia & $4.4949^{* * *}$ & $6.1303^{* * *}$ & $7.3022^{* * *}$ & $8.0564^{* * *}$ & $8.9165^{* * *}$ \\
\hline VAR(1): US & $3.7091^{* * *}$ & $5.6592^{* * *}$ & $6.8437^{* * *}$ & $7.6627^{* * *}$ & $8.4946^{* * *}$ \\
\hline $\begin{array}{c}\text { AR(1): South } \\
\text { Korea }\end{array}$ & $2.7647^{* * *}$ & $3.8914^{* * *}$ & $4.7838^{* * *}$ & $5.3186^{* * *}$ & $5.8066^{* * *}$ \\
\hline VAR(1): China & 2.8390 & $3.8367^{* * *}$ & $4.6207^{* * *}$ & $5.1065^{* * *}$ & $5.5088^{* * *}$ \\
\hline $\begin{array}{c}\operatorname{VAR}(1): \\
\text { European Area }\end{array}$ & 2.4365 & $3.5997^{* * *}$ & $4.4920^{* * *}$ & $4.9825^{* * *}$ & $5.4066^{* * *}$ \\
\hline VAR(1): Japan & 2.6064 & $3.7000^{* * *}$ & $4.6409^{* * *}$ & $5.1466^{* * *}$ & $5.5562^{* * *}$ \\
\hline $\begin{array}{c}\text { VAR(1): South } \\
\text { Korea } \\
\end{array}$ & 2.9319 & $4.0673^{* * *}$ & $5.0219^{* * *}$ & $5.5583^{* * *}$ & $6.0731^{* * *}$ \\
\hline VAR(1): US & 2.2531 & $3.1255^{* * *}$ & $4.0849^{* * *}$ & $4.6767^{* * *}$ & $5.0408^{* * *}$ \\
\hline
\end{tabular}

Given the strong evidence of nonlinearity in all the relationships between stock returns of these economies and the various EPUs, we now turn our attention to the causality-in-quantiles test for both stock return and its volatility, as presented in Figures 1 to 6 over the quantile range of 0.10 to 0.90 . Starting with Hong Kong in Figures 1 and 2, we observe that there is no evidence of 
either its own EPU or the EPU of China, the European Area, Japan and the US in containing any information of predictability for the stock return and volatility, at any part of the conditional distribution. In other words, for Hong Kong, domestic or global EPU does not cause stock return and volatility, irrespective of how the stock market is performing, i.e., in bear, normal or bull modes. Figures 3 and 4 present the results for Malaysian stock return and volatility predictability. While, there is no evidence of predictability for the Malaysian stock return from any EPUs, volatility is predictable over its entire conditional distribution by all the EPUs. Close observation suggests that the strongest predictor of volatility of the Malaysian stock return comes from Japanese EPU at the lower end (bear regime) of the conditional distribution (i.e., quantile range of 0.10 to 0.30), while the European Area EPU is the best predictor around the median (normal regime) of the distribution (i.e., quantile range of 0.40 to 0.60 ), with the US and Chinese EPUs predicting the best at the upper quantiles (bull regime), i.e., 0.70-0.80, and 0.90 respectively. So even though the EPU of Malaysia is important in predicting its own stock return volatility, the global EPUs are relatively more important at various parts of the conditional distribution. Finally, we turn to the case of South Korea in Figures 5 and 6. For the case of returns, predictability is observed to originate most strongly from the US EPU over the quantile range of 0.30 to 0.70 , while Japanese EPU has the strongest predictability for the quantile level of 0.80 . Note that, predictability at quantile 0.70 is also witnessed (in order of strength) for Japanese, South Korean and Chinese EPUs. Based, on these results, it can be said that for South Korea, predictability of its stock return is mainly driven by the US and is concentrated around the lower-middle to upper-tail parts of the distribution. In terms of stock return volatility, the most important role is played by the South Korean EPU itself from around the median till quantile range of 0.70 . The US EPU also has some predictive capability, but weaker than that of the own-EPU of South Korea at quantile level of 0.60. So, for South Korean stock returns, while US EPU plays the dominant role in predicting the stock returns of South Korea, the domestic EPU is more important in predicting stock return volatility, with predictability concentrated, in general, when the market is performing normal to well. Our results based on the causality-inquantiles approach, barring the case of Hong Kong, provides strong evidence of predictability for Malaysian stock return volatility, and South Korean stock return and volatility emanating from both domestic and global EPUs at different phases of the stock markets - something not possible based on standard, conditional mean-based and evidently misspecified, linear Granger causality tests. 
Figure 1. Causality-in-quantiles for Stock Returns of Hong Kong

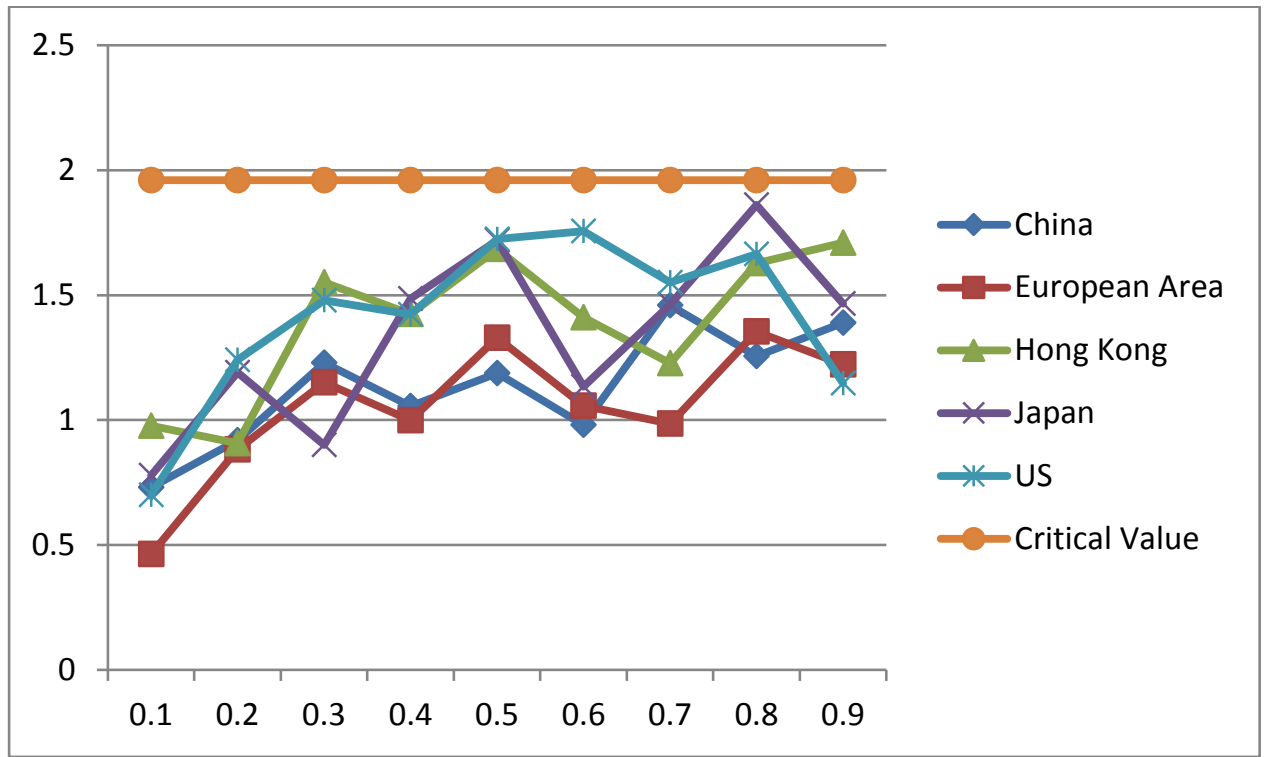

Note: Horizontal axis depicts the various quantiles, while the vertical axis presents the test statistic.

Figure 2. Causality-in-quantiles for Stock Returns Volatility of Hong Kong

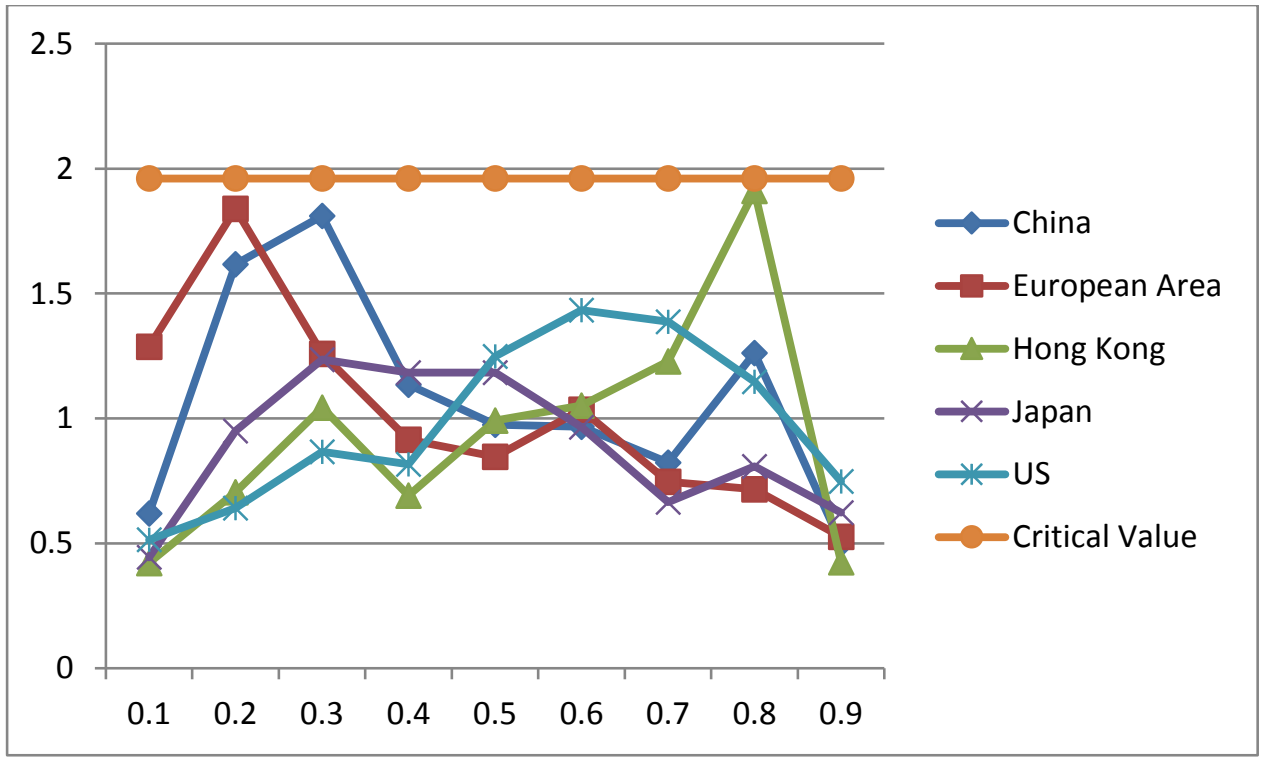

Note: See Notes to Figure 1. 
Figure 3. Causality-in-quantiles for Stock Returns of Malaysia

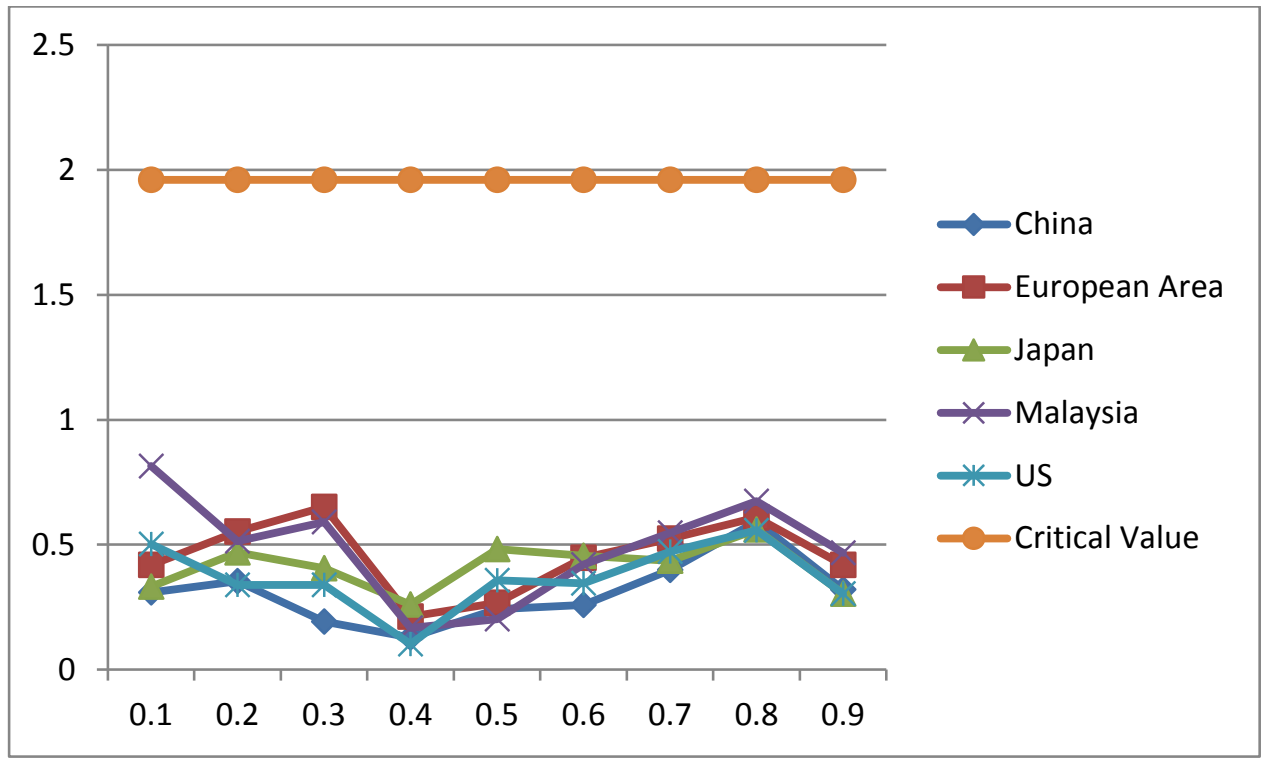

Note: See Notes to Figure 1.

Figure 4. Causality-in-quantiles for Stock Returns Volatility of Malaysia

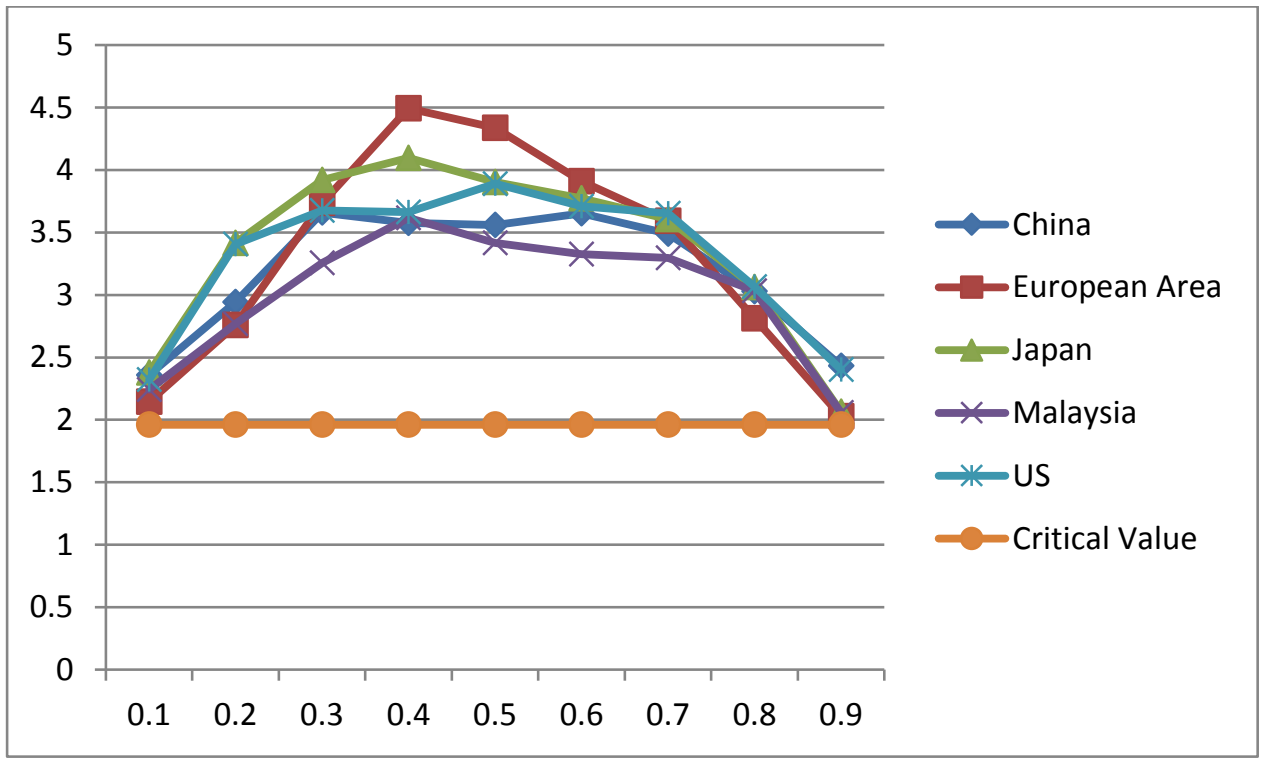

Note: See Notes to Figure 1. 
Figure 5. Causality-in-quantiles for Stock Returns of South Korea

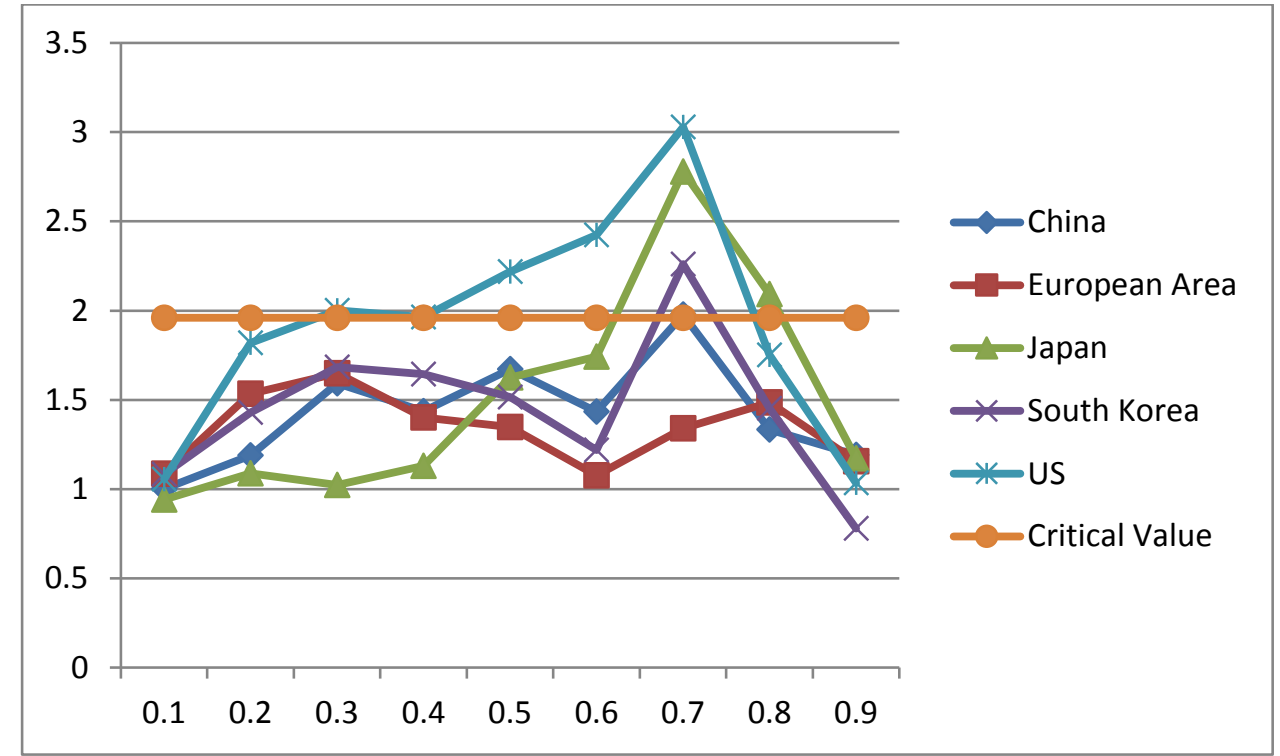

Note: See Notes to Figure 1.

Figure 6. Causality-in-quantiles for Stock Returns Volatility of South Korea

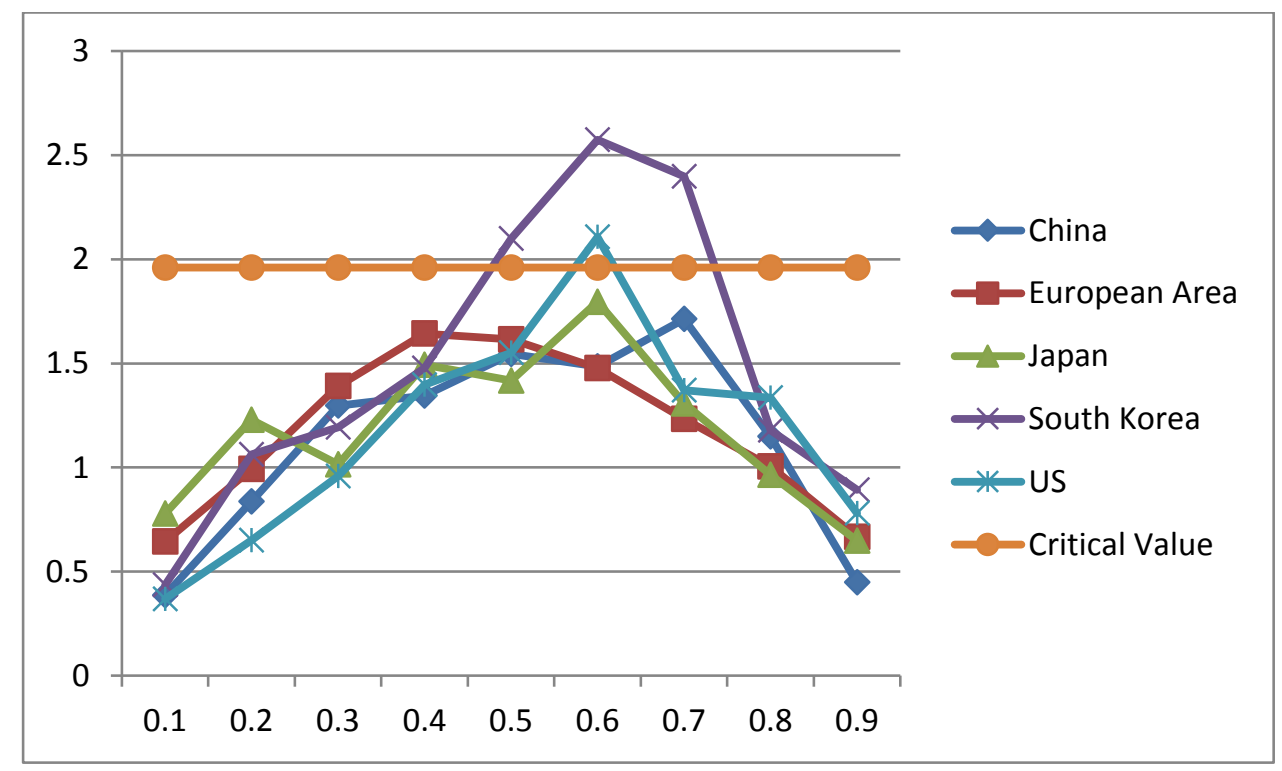

Note: See Notes to Figure 1.

In sum, based on the predictive content on domestic and global EPUs, our analysis concludes that the efficient market hypothesis holds in Hong Kong, but the same cannot be said for Malaysia and South Korea. For Malaysia, our results highlight the importance of looking at higher order causality, since one would have suggested that efficient market hypothesis holds for Malaysia as well just like Hong Kong, with EPUs playing no roles in predicting returns. However, higher moment effects, i.e., in risks involved in the market is found to be affected by both 
domestic and global EPUs, with foreign uncertainty being more important than domestic uncertainty. This result possibly highlights the vulnerability of the Malaysian market to global uncertainty. In addition, our results tend to suggest that, when the market is in bull-phase with higher returns and higher risks, investors tend to rely on information from the uncertainty associated with two of its major trading partners, i.e., the US and China. Relying on information of uncertainty from these two markets perhaps provides the investors to better price risk in their assets. While, the EPUs of China and the US is still important, when volatility is low during the bear-regime or is in average mode, the investors seem to gather more information from uncertainty measures of Japan and the Euro Area. The fact that Malaysian stock market is in a bear-regime, could be a result of the equity markets of the China and US also being in a downturn possibly due to high uncertainty ${ }^{5}$ - something that should not be surprising given the global dominance of these two markets. In such a situation, investors in Malaysia could be looking at the uncertainty of other important economies like Japan (also an important trading partner) and the Euro Area in predicting the volatility, since information content coming from high-level of uncertainties in China and the US might not be of much value in pricing risks in assets.

In terms of returns, the global dominance of the US stock market for other economies around the world seems to hold for South Korea, except when the market is doing poorly. In the bearish mode, the investors seem to rely only on past information of the South Korean stock returns and nothing else. The dominant impact of the US, along with Japan, and to some extent China, besides is own-level of uncertainty, is also understandable given the importance these countries have with South Korea in terms of trade linkages, given that the China, US, and Japan (in that order) are its most important trading partners. It seems that, when the market is doing well, investor wants to ensure their profitability by using information on uncertainty levels from the domestic and global economies, and hence EPUs matter. While, the importance of US is observed to certain degree when predicting risks (i.e., volatility) in the market, what seems to be of importance to investors is primarily the domestic level of EPU, and again that too at the upper end of the conditional distribution, i.e., when the stock market is bullish and risks are high. When risk is low, investors do not seem to rely on any information associated with domestic global EPUs.

Our results have important implications for investors who needs real-time prediction of stock returns and volatility for portfolio allocation. We show that, uncertainty matters, but its effect is

${ }^{5}$ The literature on EPU and stock markets discussed in the introduction tends to suggest a negative (positive) relationship between returns (volatility) and uncertainty. 
time-varying in the sense that it is contingent on the phase the stock market is in. Having said all this, it is important to point out that the model that we use in this paper is atheoretical, and consists of only stock returns or volatility and domestic or global EPUs. Being a non-structural model to draw conclusions about the exact reasons behind the results that we observe involves speculation. But it must be realized, that the objective of this paper was primarily to make a first attempt to use a nonparametric causality-in-quantiles framework to analyze whether uncertainty can predict stock returns and volatility of three important East Asian markets. Providing detailed explanation of the results would require future analysis based on a theoretical framework of equity markets and measures of uncertainty.

\section{Conclusion}

In an interdependent world economy, it can be hypothesized that uncertainty of major economies is likely to predict stock returns and volatility of emerging markets like Hong Kong, Malaysia and South Korea, over and above the domestic uncertainty. Against this backdrop, we use a nonparametric causality-in-quantiles test (proposed by Balcilar et al., (2017)) to verify our null hypothesis based on economic policy uncertainty (EPU) of China, the European Area, Japan, and the US, and the respective EPUs of Hong Kong, Malaysia and South Korea, over a monthly period of 1997:01-2012:03. For the sake of comparability, we started off with the standard linear Granger causality test, which, in turn, revealed that, barring the case of South Korean EPU's predictability for its own stock returns, there is no evidence of predictability originating from the various EPUs. However, the results from the conditional mean-based linear Granger causality test cannot be deemed robust, since the linear model is found to be misspecified due to the strong evidence of nonlinearity in the stock returns of these three economies, and in its relationship with the various EPUs. Given this, when we apply the nonparametric causality-in-quantiles test, which is robust to model misspecification due to nonlinearity, we find the following: (a) Domestic and global EPUs cannot predict either stock return or its volatility for Hong Kong; (b) For Malaysia, domestic and global EPUs can predict stock return volatility over its entire conditional distribution, but no evidence for the same is found for stock returns,; (c) For South Korea, global EPUs carry more information in predicting stock returns, while domestic EPU is more important for predicting volatility of stock returns, with predictability concentrating in certain parts of the conditional distributions of return and its volatility, which in turn, corresponds to the normal and bearish regimes of the market; (d) In general, our results highlight the importance of accounting for nonlinearity when predicting 
stock returns and its volatility based on EPUs, especially for Malaysia and South Korea, and; (e) Our results on predictability have important implications. Financial market returns and its volatility (often associated with uncertainty) are among the most important indicators for practitioners in finance, as its helps them in capital budgeting and portfolio management decisions as they directly reflect companies' financial health and future prospects (Poon and Granger, 2003). Whilst for academics, predictability of financial market movements, challenges the idea of market efficiency, and in turn, assists in building realistic asset pricing models (Rapach and Zhou, 2013). Hence, predicting financial market returns and volatility is of paramount importance to both practitioners and academics in finance, and clearly domestic and global EPUs have a role to play when we allow for nonlinearity and study the entire conditional distributions of returns and volatility for Malaysia and South Korea. For Hong Kong, based on the lack of information content of domestic and global EPUs in affecting stock returns and volatility, it seems that the efficient market hypothesis holds

One weakness of our study is the fact that our data sample ends in 2012:03 due to lack of data on measures of EPUs beyond this period for the three economies under consideration. Given this, our analysis misses the impact of uncertainty-related events that took place after the first quarter of 2012 on the equity markets of Hong Kong, Malaysia and South Korea, even though we do cover major stock-market related events like the East Asian crisis, the recent global financial crisis and the European sovereign debt crisis. As part of future analysis, it would be interesting to extend our study with updated data, if and when available. In addition, it would also be worthwhile to check if our results continue to hold over an out-of-sample (as in Bonaccolto et al., (2015), since in-sample predictability does not guarantee favorable forecasting results (Rapach and Zhou, 2013). 


\section{References}

Aastveit, K. A., Natvik, G. J., Sola, S., 2013. Economic uncertainty and effectiveness of monetary policy. Norges Bank Working Paper N. 17.

Alessandri, P., Mumtaz, H., 2014. Financial regimes and uncertainty shocks. Working Papers 729, Queen Mary University of London, School of Economics and Finance.

Antonakakis, N., Chatziantoniou, I., Filis, G., 2013. Dynamic co-movements between stock market returns and policy uncertainty. Economics Letters 120(1), 87-92.

Baker, S., Bloom, N., Davis, S., 2015. Measuring Economic Policy Uncertainty. NBER Working Paper 21633.

Balcilar, M., Bekiros, S., and Gupta, R., 2017. The role of news-based uncertainty indices in predicting oil markets: a hybrid nonparametric quantile causality method. Empirical Economics 53(3), 879-889.

Balcilar, M., Gupta, R., and Kyei, C., 2016. South African Stock Returns Predictability using Domestic and Global Economic Policy Uncertainty: Evidence from a Nonparametric Causalityin-quantiles Approach. Frontiers in Finance and Economics, 13(1), 10-37.

Balcilar, M., Gupta, R. Sousa, R.M., and Wohar, M.E. 2017. Do cay and cayMS predict stock and housing returns? Evidence from a nonparametric causality test. International Review of Economics and Finance, 48(1), 269-279.

Bekiros, S., Gupta, R., Kyei, C., 2016. On Economic Uncertainty, Stock Market Predictability and Nonlinear Spillover Effects. North American Journal of Economics and Finance 36, 184-191.

Bekiros, S., Gupta, R., and Majumdar, A., 2016. Incorporating Economic Policy Uncertainty in US Equity Premium Models: A Nonlinear Predictability Analysis. Finance Research Letters 18, 291 296.

Ben Nasr, A., Lux, T., Ajmi, A.N., and Gupta, R. 2016. Forecasting the Volatility of the Dow Jones Islamic Stock Market Index: Long Memory vs. Regime Switching. International Review of Economics and Finance 45(1), 559-571.

Bloom, N., 2009. The Impact of Uncertainty Shocks. Econometrica 77 (3), 623-685.

Bonaccolto, G., Caporin, M., and Gupta, R., 2015. The dynamic impact of uncertainty in causing and forecasting the distribution of oil returns and risk. Department of Economics, University of Pretoria, Working Paper No. 201564.

Brock, W., Dechert, D., Scheinkman, J., LeBaron, B., 1996. A test for independence based on the correlation dimension. Econometric Reviews 15 197-235.

Brogaard, J., Detzel. A., 2015. The asset pricing implications of government economic policy uncertainty. Management Science 61(1), 3-18.

Carriero, A., Mumtaz, H., Theodoridis, K., Theophilopoulou, A., 2015. The Impact of Uncertainty Shocks under Measurement Error. A Proxy SVAR Approach. Journal of Money, Credit and Banking 47(6), 1223-1238. 
Chang, T., Chen, W. Y., Gupta, R., Nguyen. D. K., 2015. Are Stock Prices Related to Political Uncertainty Index in OECD Countries? Evidence from Bootstrap Panel Causality Test. Economic Systems 39(2), 288-300.

Chiang, T.C., and Chen, X. 2016. Stock returns and economic fundamentals in an emerging market: An empirical investigation of domestic and global market forces. International Review of Economics \& Finance, 43(1), 107-120.

Choi, K. H., Yoon, S. M., and Kang, S. H., 2013. Relationship between Stock Returns and Trading Volume: Domestic and Cross-Country Evidence in Asian Stock Markets. Proceedings of the 2013 International Conference on Economics and Business Administration, 33-39.

Chuliá, H., Guillén, M., and Uribe, J. M., 2015. Measuring Uncertainty in the Stock Market. Research Institute of Applied Economics Working Paper No. 2015/24.

Colombo, V., 2013. Economic Policy Uncertainty in the US: Does it Matter for the Euro Area? Economics Letters 121 (1), 39-42.

Gebka, B., Wohar M. E., 2013. Causality between trading volume and returns: Evidence from quantile regressions. International Review of Economics and Finance 27, 144-159

Gupta. R., Hammoudeh. S., Modise. M. P., Nguyen. D. K., 2014. Can economic uncertainty, financial stress and consumer sentiments predict US equity premium? Journal of International Financial Markets, Institutions and Money 33, 367-378.

Han, H., Kutan, A. M., and Ryu, D., 2015. Modeling and predicting the market volatility index: The case of VKOSPI. Economics Discussion Papers, No. 2015-7.

Jais, M., Jakpar, S., Doris, T. K. P., and Shaikh, J. M. 2012. The financial ratio usage towards predicting stock returns in Malaysia. International Journal of Managerial and Financial Accounting, 4(4), $377-401$.

Jarrett, J. E., 2008. Predicting daily stock returns: a lengthy study of the Hong Kong and Tokyo stock exchanges. International Journal of Business and Economics, 7(1), 37-51.

Jeong, K., Härdle, W. K., Song, S., 2012. A consistent nonparametric test for causality in quantile. Econometric Theory 28(04), 861-887.

Jones, P. M., Olson, E., 2013. The Time-Varying Correlation between Uncertainty, Output, and Inflation: Evidence from a DCC-GARCH Model. Economics Letters 118 (1), 33-37.

Jordan, S.J., Vivian, A., and Wohar, M.E. 2016. Can commodity returns forecast Canadian sector stock returns? International Review of Economics \& Finance, 41(1), 172-188.

Jurado, K., Ludvigson, S. C., Ng, S., 2015. Measuring uncertainty. The American Economic Review 105, 1177-1216.

Kang, W., Ratti, R.A., 2013. Oil shocks, policy uncertainty and stock market returns. Journal of International Financial Markets, Institutions and Money 26(1), 305-318.

Kang, W., Ratti, R.A., 2015. Oil shocks, policy uncertainty and stock returns in China. Economics of Transition23(4), 657-676. 
Karnizova, L., Li, J. C., 2014. Economic policy uncertainty, financial markets and probability of US recessions. Economics Letters 125, 261-265.

Li. X-L., Balcilar. M., Gupta. R., Chang. T., 2016. The Causal Relationship between Economic Policy Uncertainty and Stock Returns in China and India: Evidence from a Bootstrap RollingWindow Approach. Emerging Markets Finance and Trade 52 (3), 674-689.

Mensi, W., Hammoudeh, S., Reboredo, J. C., Nguyen, D. K., 2014. Do global factors impact BRICS stock markets? A quantile regression approach. Emerging Markets Review 19, 1-17.

Mensi, W., Hammoudeh, S., Yoon, S-M, and Nguyen, D. K., 2016. Asymmetric Linkages between BRICS Stock Returns and Country Risk Ratings: Evidence from Dynamic Panel Threshold Models. Review of International Economics 24 (1), 1-19.

Momin, E., and Masih, M., 2015. Do US policy uncertainty, leveraging costs and global risk aversion impact emerging market equities? An application of bounds testing approach to the BRICS. MPRA Working Paper No. 65834.

Mumtaz, H., Surico, P., 2013. Policy Uncertainty and Aggregate Fluctuations. Working Papers 708, Queen Mary, University of London, School of Economics and Finance.

Mumtaz, H., Theodoridis, K., 2014. The changing transmission of uncertainty shocks in the US: an empirical analysis. Working Papers 735, Queen Mary University of London, School of Economics and Finance.

Mumtaz, H., Theodoridis, K., 2015. Common and Country Specific Economic Uncertainty. Working Papers 752, Queen Mary University of London, School of Economics and Finance.

Mumtaz, H., Zanetti, F., 2013. The impact of the volatility of monetary policy shocks. Journal of Money, Credit and Banking 45, 535-558.

Nishiyama, Y., Hitomi, K., Kawasak, Y., and Jeong, K., 2011. A consistent nonparametric test for nonlinear causality - Specification in time series regression. Journal of Econometrics 165, 112127.

Poon, S-H, and Granger, C. W. J., 2003. Forecasting Volatility in Financial Markets: A Review. Journal of Economic Literature, 41(2), 478-539.

Poon, W. C., and Tong, G. K., 2010. Output growth, inflation and interest rate on stock return and volatility: the predictive power. SSRN Working Paper No. 1605883.

Rapach. D., Strauss. J., Zhou. G., 2013. International Stock Return Predictability: What is the Role of the United States? Journal of Finance 68(4), 1633-1662.

Rapach, D. E., and Zhou, G., 2013. Forecasting stock returns. Handbook of Economic Forecasting, 2(Part A), Graham Elliott and Allan Timmermann (Eds.), Amsterdam: Elsevier, 328-383.

Redl, C., 2015. Macroeconomic uncertainty in South Africa. ERSA Working Paper 509, Economic research South Africa.

Rossi, B., and Sekhposyan, T., 2015. Macroeconomic Uncertainty Indices Based on Nowcast and Forecast Error Distributions. American Economic Review: Papers \& Proceedings 105(5), 650-655. 
Sum, V., 2012a. The Reaction of Stock Markets in the BRIC Countries to Economic Policy Uncertainty in the United States. SSRN Paper No. 2094697.

Sum, V., 2012b. How Do Stock Markets in China and Japan Respond to Economic Policy Uncertainty in the United States? SSRN Paper No. 2092346.

Sum, V., 2012c. The impulse response function of economic policy uncertainty and stock market puzzle: A look at the Eurozone. Journal of International Finance Studies 12(3), 100-105.

Tarazi, R. E., and Gallato, C., 2012. Determinants of Expected Stock Returns: Evidence from the Malaysian and Thai Markets. SSRN Paper No. 2167679.

Tsai, I., 2012. The relationship between stock price index and exchange rate in Asian markets: A quantile regression approach. Journal of International Financial Markets, Institutions \& Money 22, 609621.

Zakaria, Z., and Shamsuddin, S., 2012. Empirical evidence on the relationship between stock market volatility and macroeconomics volatility in Malaysia. Journal of Business Studies Quarterly, $4(2), 61-71$. 


\section{APPENDIX:}

Table A1: Unit Root Tests

\begin{tabular}{|c|c|c|c|c|c|c|c|c|c|c|c|c|c|c|c|c|}
\hline \multirow[t]{3}{*}{ Variable } & \multicolumn{4}{|c|}{ ADF } & \multicolumn{4}{|c|}{ PP } & \multicolumn{4}{|c|}{ DF-GLS } & \multicolumn{4}{|c|}{ Ng-Perron } \\
\hline & \multicolumn{2}{|l|}{ Level } & \multicolumn{2}{|c|}{ First Difference } & \multicolumn{2}{|l|}{ Level } & \multicolumn{2}{|c|}{ First Difference } & \multicolumn{2}{|l|}{ Level } & \multicolumn{2}{|c|}{ First Difference } & \multicolumn{2}{|l|}{ Level } & \multicolumn{2}{|c|}{ First Difference } \\
\hline & Constant & $\begin{array}{l}\text { Constant } \\
+ \text { Trend }\end{array}$ & Constant & $\begin{array}{l}\text { Constant } \\
+ \text { Trend }\end{array}$ & Constant & $\begin{array}{l}\text { Constant } \\
+ \text { Trend }\end{array}$ & Constant & $\begin{array}{l}\text { Constant }+ \\
\text { Trend }\end{array}$ & Constant & $\begin{array}{l}\text { Constant } \\
+ \text { Trend }\end{array}$ & Constant & $\begin{array}{l}\text { Constant }+ \\
\text { Trend }\end{array}$ & Constant & $\begin{array}{l}\text { Constant } \\
+ \text { Trend }\end{array}$ & $\begin{array}{ll} & \text { Constant } \\
& \end{array}$ & $\begin{array}{l}\text { Constant } \\
+ \text { Trend }\end{array}$ \\
\hline $\begin{array}{l}\text { Stock } \\
\text { price } \\
\text { Malaysia }\end{array}$ & -1.806 & $-4.441 *$ & $-11.065^{*}$ & $-11.146^{*}$ & -1.418 & $-3.526^{*}$ & $-11.011 *$ & $-11.058^{*}$ & -1.534 & -1.783 & $-10.789 *$ & $-11.203 *$ & -5.068 & -6.647 & $-86.72 *$ & $-88.017^{*}$ \\
\hline $\begin{array}{l}\text { Stock } \\
\text { price } \\
\text { Hong } \\
\text { Kong }\end{array}$ & -1.699 & -3.074 & $-8.791 *$ & $-8.775^{*}$ & -1.520 & -2.682 & $-9.725 *$ & $-9.702 *$ & -1.566 & -2.609 & $-9.692^{*}$ & $-8.688^{*}$ & -5.814 & -13.616 & $-81.885^{*}$ & $-100.75^{*}$ \\
\hline $\begin{array}{l}\text { Stock } \\
\text { price } \\
\text { South } \\
\text { Korea }\end{array}$ & -1.247 & $-3.648^{*}$ & $-9.277 *$ & $-9.262^{*}$ & -1.056 & -3.114 & $-9.16^{*}$ & $-9.143^{*}$ & -0.763 & -2.846 & $-8.491 *$ & $-9.139 *$ & -2.174 & -16.032 & $-74.175^{*}$ & $-78.639 *$ \\
\hline $\begin{array}{l}\text { EPU } \\
\text { Malaysia }\end{array}$ & $-3.844 *$ & $-3.892^{*}$ & --- & --- & $-4.994 *$ & $-5.057 *$ & --- & --- & $-3.26^{*}$ & $-3.837 *$ & --- & --- & $-19.54 *$ & $-25.93^{*}$ & --- & --- \\
\hline $\begin{array}{l}\text { EPU } \\
\text { Hong } \\
\text { Kong }\end{array}$ & $-6.687 *$ & $-6.762^{*}$ & --- & --- & $-6.737 *$ & $-6.808^{*}$ & --- & --- & $-3.092^{*}$ & $-3.575^{*}$ & --- & --- & $-17.75^{*}$ & $-23.98^{*}$ & --- & -- \\
\hline $\begin{array}{l}\text { EPU } \\
\text { South } \\
\text { Korea }\end{array}$ & $-4.347^{*}$ & $-8.704 *$ & --- & --- & $-7.831 *$ & $-8.923^{*}$ & -- & --- & $-2.36^{*}$ & $-8.286^{*}$ & --- & --- & $-11.88^{*}$ & $-72.56^{*}$ & --- & --- \\
\hline $\begin{array}{l}\text { EPU } \\
\text { European } \\
\text { Area }\end{array}$ & $-4.085^{*}$ & $-4.973^{*}$ & --- & --- & $-3.735^{*}$ & $-4.801 *$ & --- & --- & $-3.971 *$ & $-4.778^{*}$ & --- & --- & $-27.75^{*}$ & $-36.34 *$ & -- & --- \\
\hline
\end{tabular}




\begin{tabular}{|c|c|c|c|c|c|c|c|c|c|c|c|c|c|c|c|c|}
\hline $\begin{array}{l}\text { EPU } \\
\text { China }\end{array}$ & $-3.502 *$ & $-7.163^{*}$ & --- & --- & $-6.128^{*}$ & $-7.208^{*}$ & --- & --- & $-2.572^{*}$ & -2.945 & --- & --- & $-12.03^{*}$ & -15.347 & --- & --- \\
\hline $\begin{array}{l}\text { EPU } \\
\text { Japan }\end{array}$ & $-5.571 *$ & $-5.689 *$ & --- & -- & $-8.819 *$ & $-8.994 *$ & --- & --- & $-5.51 *$ & $-5.57 *$ & --- & --- & $-44.71 *$ & $-45.55^{*}$ & --- & -- \\
\hline $\begin{array}{l}\text { EPU } \\
\text { United } \\
\text { States }\end{array}$ & $-5.709 *$ & $-6.759 *$ & --- & --- & $-5.523^{*}$ & $-6.759 *$ & -- & -- & $-5.459 *$ & $-6.59 *$ & --- & -- & $-44.34^{*}$ & $-56.82^{*}$ & --- & --- \\
\hline
\end{tabular}

Note: $*$ denote rejection of null hypothesis of unit root at $5 \%$ level of significance. 
Figure A1(a): Plot of Stock Returns

HONGKONG

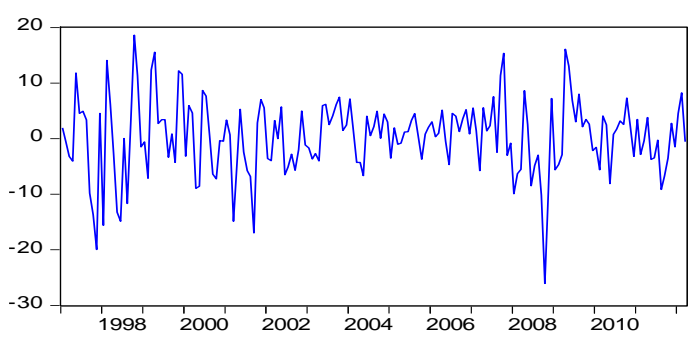

SOUthKorea

Figure A1(b): Plot of EPUs
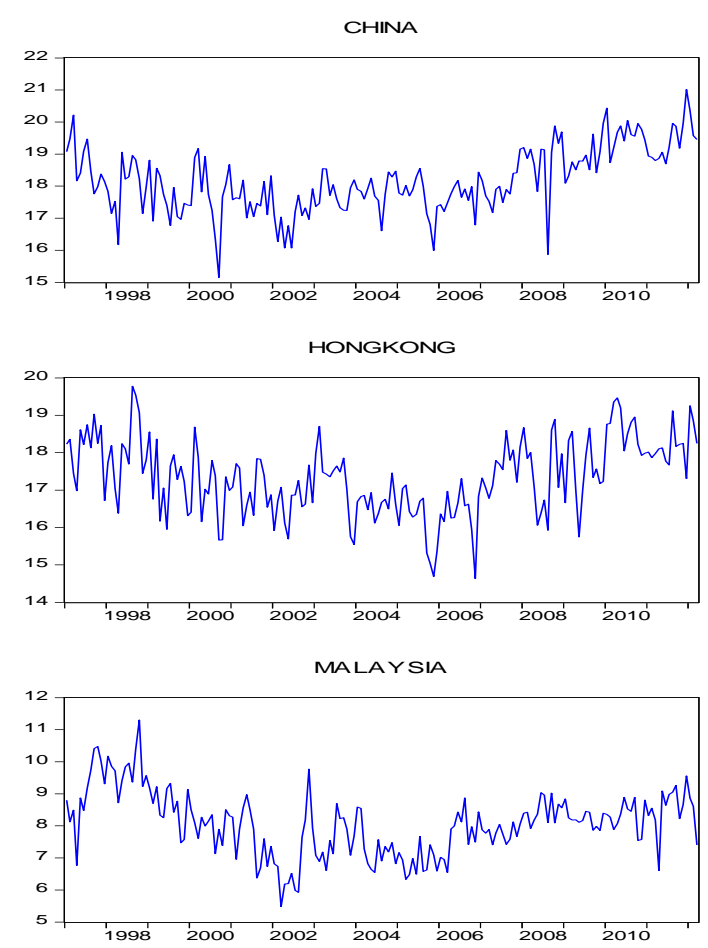

us

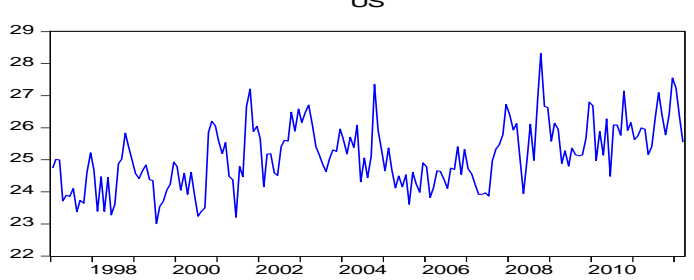

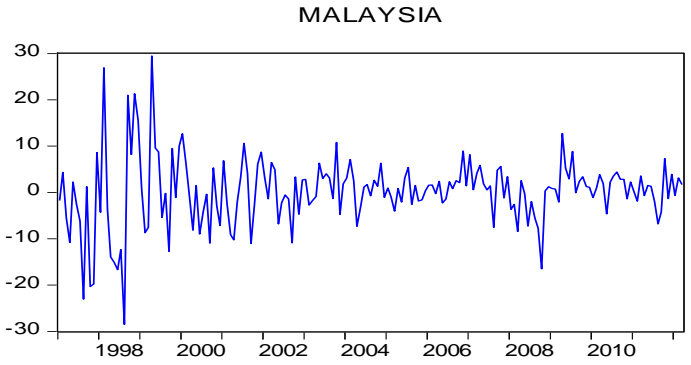
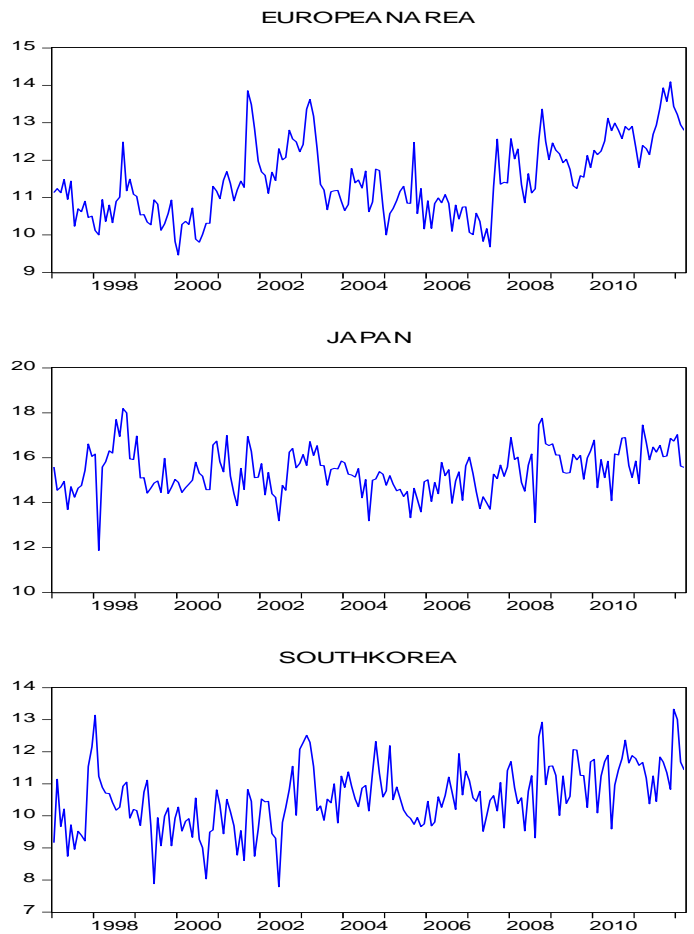